\title{
Influence of tire temperature conditions on the capacity of quarry dump trucks operated in JSC "CC Kuzbassrazrezugol"
}

\author{
Alexander Kulpin ${ }^{1 *}$, Mikhail Dadonov ${ }^{1}$, Evdokia Kulpina ${ }^{2}$, Valery Borovtsov $^{3}$, and Zhanar \\ Kaisanova $^{4}$ \\ ${ }^{1}$ T.F. Gorbachev Kuzbass State Technical University, Department of Vehicle Operation, 650000, \\ Kemerovo, 28 Vesennyaya st., Russian Federation \\ ${ }^{2}$ T.F. Gorbachev Kuzbass State Technical University, Department of Production Management, \\ 650000, Kemerovo, 28 Vesennyaya st., Russian Federation \\ ${ }^{3}$ T.F. Gorbachev Kuzbass State Technical University, Department of foreign languages, 650000, \\ Kemerovo, 28 Vesennyaya st., Russian Federation \\ ${ }^{4}$ Kazakh Humanitarian Law Innovative University, Department of Information and Technical \\ Sciences
}

\begin{abstract}
More than $50-60 \%$ of minerals in Russia and the CIS countries are mined in an open-pit or in mining quarry, as it is the most economical and productive. JSC "CC Kuzbassrazrezugol" ranks second in terms of total coal production among the regions of the Russian Federation and first in Kuzbass. Quarry dump trucks are the main mode of technological transport when transporting mined rock. An important task facing road transport is to reduce the cost of transported products. The components of the costs include fuel, tires, maintenance and repair, maintenance of roads and others. It is possible to reduce tires costs by controlling tires life. Most often, thermal damage causes the emergency decommissioning of tires. It is possible to maintain the optimal temperature regime of quarry dump truck tires with the help of operating modes such as load capacity utilization factor and speed, as well as operating conditions such as ambient temperature and longitudinal slope of the road. In turn, the performance of quarry dump trucks directly depends on the operating modes. On the one hand, the growing utilization factor of load capacity and speed increase the productivity of quarry dump trucks, but at the same time this increases the temperature regime and reduces their reliability. This article proposes a methodology for determining the maximum productivity of quarry dump trucks operated in CC Kuzbassrazrezugol taking into account the temperature regime of tires.
\end{abstract}

\footnotetext{
${ }^{*}$ Corresponding author: kulpinag $@$ kuzstu.ru
} 


\section{Introduction}

Despite the global trend to reduce the use of hydrocarbon, including solid fuels, coal is widely used in various industries, both in the Russian Federation and abroad. At the same time, the open or quarrying method remains the most productive and economical method of coal mining. In Russia and the CIS countries, more than $50 \%$ of minerals are mined by open extraction method. Kuzbass occupies one of the leading places in terms of total coal production among the regions of the Russian Federation. Kuzbass coal enterprises produce more than 300 million tons of coal annually (Fig. 1). And among them, a special place is occupied by CC Kuzbassrazrezugol JSC, which owns the Bachatsky, Kaltansky, Kedrovsky, Krasnobrodsky, Mokhovsky and Taldinsky coal quarrys. At these enterprises, the total annual coal production reaches almost 50 million tons (Fig. 1). This allows CC Kuzbassrazrezugol JSC to occupy confidently the second place in coal production (more than $11 \%$ of the total volume) in the territory of the Russian Federation and the first in Kuzbass (about $20 \%$ of the total volume).

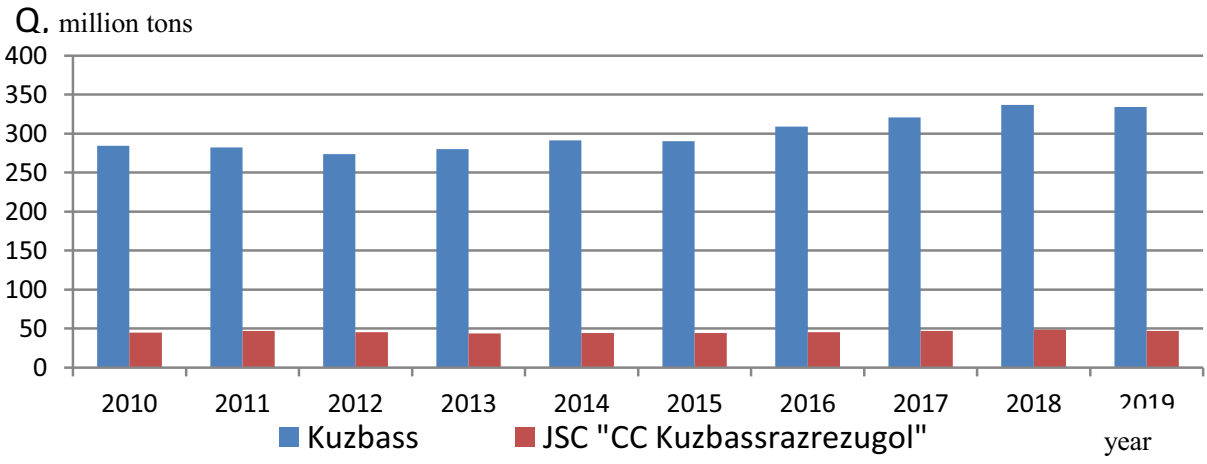

Fig. 1. Annual coal production volumes in Kuzbass, including in JSC "CC Kuzbassrazrezugol".

Coal mining is a complex multi-stage process in which transportation is the most expensive and the labor-intensive stage. And as the work deepens, the share of transport costs is steadily growing. The main mode of technological transport in the open production method is road transport [1-4]. Process dump trucks allow mining operations to be carried out at almost any depth, in any climatic conditions, in combination with any other types of technological transport [5-7]. At the same time, the costs associated with the operation of mine dump trucks exceed the costs of other technological transport types and the efficiency of their operation has a significant impact on the cost of the coal mining process. The cost of producing one ton of coal in an open manner using process vehicles consists of more than half of the transportation costs, most of which are fuel and tire costs (Figure 2) [8-13]. 

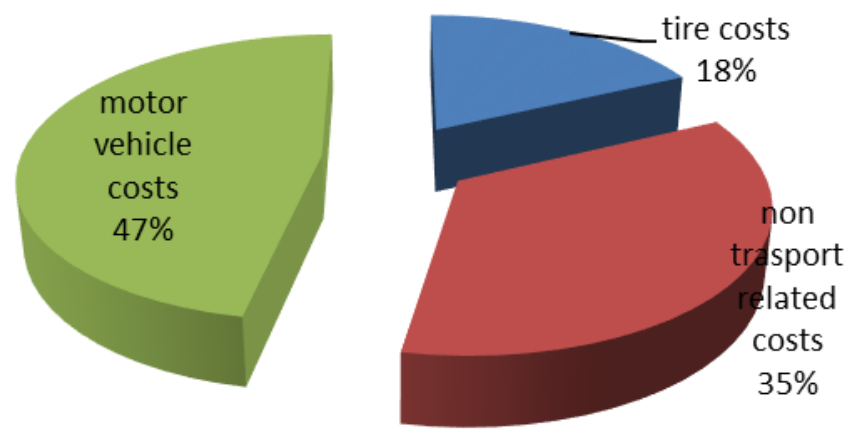

Fig. 2. Costs structure for rock mass transportation.

One of the priority tasks solved by mining enterprises as part of the strategy to increase the efficiency of the quarry vehicles use should be the task of minimizing the emergency share unscheduled outages of quarry trucks. The averaged structure of the emergency downtime causes of quarry dump trucks at the enterprises of JSC "CC Kuzbassrazrezugol" is presented in Fig. 3.

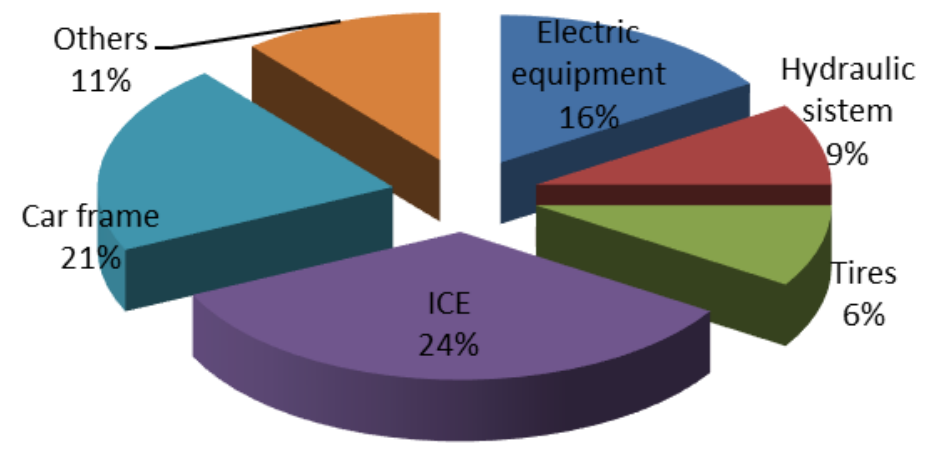

Fig. 3. Downtime unscheduled structure of quarry dump trucks for technical reasons.

Given the share of operating costs for tires, the task of increasing their resource is significant, regardless of the mining and climatic conditions of the vehicle.

The main reasons for the write-off of tires in JSC "CC Kuzbassrazrezugol" are:

- operating wear - $81 \%$;

- thermal destruction - $15 \%$;

- mechanical damages - 3\%;

- factory marriage - $1 \%$.

Thermal destruction, mechanical damage and factory failure lead to premature failure of the tires [14-20].

Any tire is heated during movement and depending on the conditions and modes of operation, reaches a certain temperature range. The higher it is, the greater the probability of irreversible structural changes leading to thermal damage to the tire. The type of thermal destruction is shown in Fig. 4. 

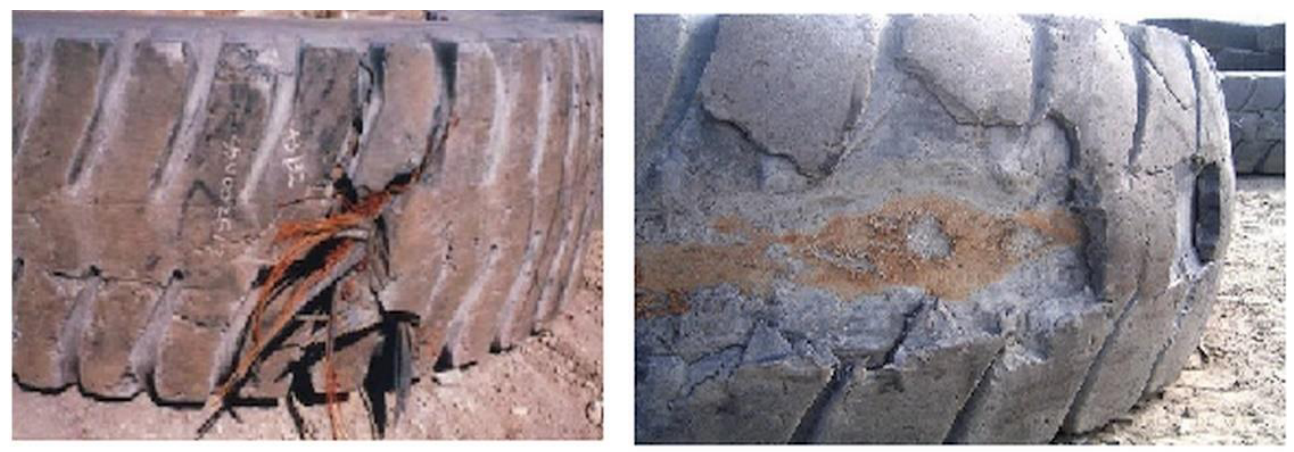

Fig. 4. Tire damage due to thermal failure.

The tire temperature range of $60-70^{\circ} \mathrm{C}$ is considered optimal, $90-100^{\circ} \mathrm{C}$ - working, and $110-120^{\circ} \mathrm{C}$ - critical. Thermal damage is accompanied by cord rupture, tread peeling or tire ignition. When the quarry dump truck is moving, the maximum heat generation in the tire occurs in the contact zone with the supporting surface. Studies showed that the greatest heat is released in the middle of the breaker layer of the tire and then distributed as follows - about half on the tread, about $30 \%$ on the frame, the breaker layer - up to $15 \%$, the sidewall - up to $20 \%$ [21-23].

It was revealed that the main factors affecting the temperature regime of tires during operation are (as the degree of influence decreases):

- ambient air temperature;

- coefficient load capacity use;

- average operating speed of the quarry dump truck;

- longitudinal slope of the road.

The analysis of the obtained experimental data let do an equation of multiple dependence on these factors in the following form:

$$
\mathrm{T}_{T}=T_{a}+a \cdot \gamma+b \cdot V_{s}+c \cdot i+d
$$

where $\mathrm{a}, \mathrm{b}, \mathrm{c}, \mathrm{d}$ - constant coefficients

$T_{\tau}$-- tire temperature, ${ }^{\circ} \mathrm{C}$;

$T_{a}$ - ambient air temperature, ${ }^{\circ} \mathrm{C}$;

$\gamma$ - coefficient load capacity use

$V_{s}$ - average operating speed, $\mathrm{km} / \mathrm{h}$;

${ }^{i}$ - longitudinal slope of the road, $\%$.

Ambient air temperature and longitudinal slope of the road are factors which are taken into consideration, and coefficient load capacity use and average operating speed are controlled factors for thermal condition of tires and main components of capacity of dump trucks. Hourly capacity $\left(W_{\tau \cdot \mathrm{ks}}\right)_{\text {is }}$ determined by the formula

$$
W_{\mathrm{T} \cdot \mathrm{km}}=\frac{q \cdot \gamma \cdot V_{T} \cdot \beta \cdot L_{c}}{L_{\mathrm{c}}+T_{p t} \cdot V_{T} \cdot \beta}, t \cdot k \mathrm{~m} / \mathrm{h}
$$

where $q^{-}$load capacity of quarry dump truck, $\mathrm{t}$;

$\gamma$ - coefficient load capacity use

$V_{\tau}$-technical speed, $\mathrm{km} / \mathrm{h}$; 


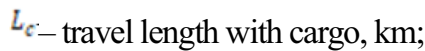

$\mathrm{T}_{p t}$ - quarry dump truck downtime per trip, h;

$\beta$ - coefficient mileage utilization (for pendulum routes $\beta=0.5$ ).

$$
\mathrm{T}_{p t}=t_{\mathrm{it}}+t_{\mathrm{ut}}+t_{w}+t_{o}, \mathrm{~h}
$$

where $^{t_{\text {it }}}$ - quarry dump truck loading time, $\mathrm{h}$;

$t_{\text {ut }}$ - quarry dump truck unloading time, h;

$t_{w}$ - waiting time for loading and unloading, h;

$t_{0}$ - other downtime, $\mathrm{h}$.

Based on the temperature mode equation, the productivity has the form:

$$
W_{T \cdot k m}=\frac{q \gamma \cdot \frac{T_{x}-T_{a}-a \gamma-c \cdot i-d}{b} \cdot \beta \cdot L_{c}}{b}, t \cdot \mathrm{km} / \mathrm{h}
$$



Fig. 5. The graphical dependence of the capacity (W) on the longitudinal slope (i) and the coefficient load capacity use $\left(\gamma_{\mathrm{r}}\right)$ at the ambient temperature of $30^{\circ} \mathrm{C}$ 


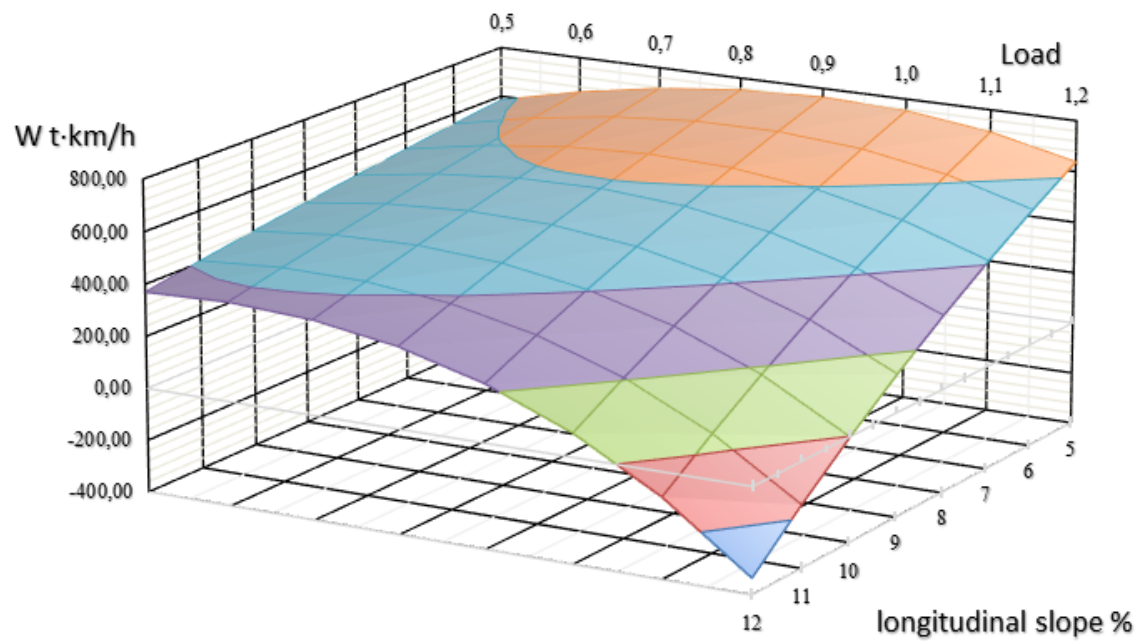

Fig. 6. The graphical dependence of the capacity (W) on the longitudinal slope (i) and the coefficient load capacity use $\left(\gamma_{\mathrm{r}}\right)$ at the ambient temperature of $40^{\circ} \mathrm{C}$

The results of the calculations show that on the one hand, an increase in load and speed entails an increase in productivity, on the other hand, causes an increase in the temperature of the tires, and, as a result, a decrease in their reliability, an increase in the number of failures, which means an increase in downtime in repairs, repair costs and a decrease in the availability factor.

Thus, the lower the coefficient load capacity use and the speed, the lower the tire temperature, but there is a low output of the quarry dump truck:

- at an ambient temperature of $+40^{\circ} \mathrm{C}$ and a slope of the quarry road of $5 \%$, the maximum capacity of the quarry dump truck is $764,66 \mathrm{tkm} / \mathrm{h}$ with the coefficient load capacity use of 0.9 and $752,71 \mathrm{tkm} / \mathrm{h}$ with the coefficient load capacity use of 1,0 , which is a difference of $1.6 \%$;

- at an ambient temperature of $+40^{\circ} \mathrm{C}$ and a slope of the quarry road of $6 \%$, the maximum capacity of the quarry dump truck is $701,55 \mathrm{tkm} / \mathrm{h}$ with the coefficient load capacity use of 0.9 and $676,37 \mathrm{tkm} / \mathrm{h}$ with the coefficient load capacity use of 1,0 , which is a difference of $3,7 \%$;

Further, at a given ambient temperature and a slope of the quarry road of $7-8 \%$, the maximum capacity of the dump truck will be at the coefficient load capacity use of 0.8 .

At an ambient temperature of $+30^{\circ} \mathrm{C}$ and a slope of the quarry road of $7-8 \%$, the maximum capacity of the quarry dump truck corresponds to the coefficient load capacity use of 0.9 , and the slope of the quarry road of $9-10 \%$, the maximum capacity of the quarry dump truck corresponds to the coefficient load capacity use of 0.8 .

Based on this equation, it can be concluded that at ambient temperature below $+30^{\circ} \mathrm{C}$, thermal damage is independent of controlled factors and quarry dump trucks can be operated at maximum speed and load.

The work is executed within the limits of the complex scientific and technical program of a full innovative cycle "Development and introduction of a complex of technologies in areas of exploration and extraction of solid minerals, maintenance of industrial safety, bioremediation, creation of new products of deep processing from coal raw materials at consecutive decrease in ecological impact on environment and risks for population life" (CSTP "Clean coal — Green Kuzbass") on event 2.5 "Development and creation of an autonomous shuttle-type dump truck with 
carrying capacity of 220 tons (JUPITER project)", with participation of T.F. Gorbachev Kuzbass State Technical University in terms of research, development and technological works.

\section{References}

1. G.M. Dubov, D.S. Trukhmanov, A.A. Chegoshev, V.E. Ashikhmin, E3S Web Conf., 41, 03008 (2018)

2. G.M. Dubov, D.S. Trukhmanov, S.A. Nokhrin, IOP Conf. Series: Earth and Environ. Sci., 459, 042059 (2020)

3. D.M Dubinkin, Mining Equipment and Electromechanics. 4, 59 (2020)

4. D. Dubinkin, V. Aksenov, M. Tyulenev, S. Markov Journal of mining and geotechnical engineering. 4, 42 (2020)

5. M.Dadonov, A. Kulpin, O.Ostanin, E. Suleimenov, E3S Web of Conferences 105, 03009 (2019)

6. M. Dadonov, A. Kulpin, V.Borovtsov, A. Zhunusbekova, E3S Web of Conferences 174, 03018 (2020)

7. A.G. Kulpin, D.V. Stenin, E.E. Kultayev, E.E. Kulpina, V.A. Borovtsov, Coal in the 21st Century: Mining, Processing and Safety,116( 2016)

8. A.G. Kulpin, D.V. Stenin, E.E. Kultayev, E.E. Kulpina, V.A. Borovtsov, Coal in the 21st Century: Mining, Processing and Safety (2016)

9. D.V. Stenin, N.A Stenina, A.A Bakanov, Coal in the 21st Century: Mining, Processing and Safety (2016)

10. X. Yang, O. Olatunbosun, D. Garcia-Pozuelo, E Bolarinwa, SAE Technical Papers (2015)

11. Q. Sunqing, D. Junxiu, Ch. Guoxu, Lubricating Science, 11:3, 165 (1999)

12. A. A Samarskii, V. A Galaktionov, S. P Kurdiumov, A.P. Mikhailow, Blow-up in quasilinear parabolic equations (Berlin, Walter de Gruytel, 1995)

13. A. Abramovich, E Pudov, E Kuzin, E3S Web of Conferences, 21, 01011 (2017)

14. A Kvasova, B Gerike, E Murko, D Skudarnov, E3S Web of Conferences, 21, 03016 (2017)

15. F. Zhang, Z., Gu, S. Zhang, X. Ma, Zhu, Y. ZhendongyuChongji, Journal of Vibration and Shock, 35:17, 71 (2016)

16. T.H. Langer, T.K. Iversen, O.O. Mouritsen, M.K. Bak, M.R. Hansen, International Journal of Vehicle Design, 65:2-3, 222 (2014)

17. J. Meech, J. Parreira, IFAC Proceedings Volumes, 15:1, 142 (2013)

18. Y. Li, W.Y. Liu, S. Frimpong, Engineering Failure Analysis, 23, 55 (2013)

19. D. Dubinkin, A. Kulpin, and D. Stenin. E3S Web of Conferences. 174, 03015 (2020)

20. R. Larson, J. Cuadrado, SAE International Journal of Commercial Vehicles, 5:1, $101(2012)$

21. K. Pal, T. Das, Polymer Engineering and Science, 48:12, 2410 (2008)

22. T. Eguchi, T. Muro, 15th International Conference of the International Society for Terrain Vehicle Systems (2005)

23. P.F. Knights, A.L. Boerner, Mining Engineering, 53:8, 51 (2001) 